\title{
O desenvolvimento como alargamento das capacidades humanas: aproximações entre Amartya Sen e Celso Furtado
}

\author{
Dellany Maria Dantas Souza \\ Mestranda no Programa de Pós-Graduação em Desenvolvimento Regional na Universidade Estadual da Paraíba \\ (Uepb) \\ Angela Maria Cavalcanti Ramalho
} Programa de Pós-Graduação em Desenvolvimento Regional da Universidade Estadual da Paraíba (Uepb)

Leonardo de Araújo e Mota

Programa de Pós-Graduação em Desenvolvimento Regional da Universidade Estadual da Paraíba (Uepb)

Recebido: 27/06/2014 Versão revisada (entregue): 09/12/2014 Aprovado: 16/02/2015

\begin{abstract}
Resumo
O sentido do termo desenvolvimento muito se alargou e hoje existe um reconhecimento de que o mero crescimento econômico não é obrigatoriamente sinônimo de desenvolvimento. Neste sentido, este artigo tem como objetivo analisar o conceito de desenvolvimento como alargamento das capacidades humanas. Para tanto, busca-se discorrer sobre o que é desenvolvimento, a partir dos conceitos elaborados por Amartya Sen e Celso Furtado, para depois realizar um diálogo entre suas teorias. No decorrer da análise, observou-se uma aproximação entre Sen e Furtado acerca da essência do desenvolvimento, uma vez que os conceitos de Expansão das Potencialidades (Celso Furtado) ou Alargamento das Capacidades Humanas (Amartya Sen) estão relacionados à perspectiva do desenvolvimento em sua dimensão humana e social. Constatou-se que é possível verificar uma aproximação entre esses autores, na medida em que o desenvolvimento é entendido como o alargamento das capacidades humanas, e que tal alargamento não ocorre se não forem asseguradas as devidas condições objetivas para a sua realização.
\end{abstract}

Palavras-chave | Amartya Sem; capacidades humanas; Celso Furtado; desenvolvimento.

Código JEL | B50; O10; O15.

\section{THE DEVELOPMENT AS ENLARGEMENT OF HUMAN CAPABILITIES: SIMILARITIES BETWEEN AMARTYA SEN AND CELSO FURTADO}

\section{Abstract}

The meaning of the term development has been expanded significantly and nowadays there is recognition that mere economic growth is not necessarily synonymous of development. Thus, 
this article aims to examine the concept of development as the enlargement or the expansion of human capabilities. To achieve this task, it seeks to discuss what is the meaning of development based on the Amartya Sen and Celso Furtado concepts, and then carry out a dialogue with their theories. The methodology used was bibliographical research, applied to the analysis of the texts of the chosen authors for a comparative discussion. During the analysis, there we discovered connections between Sen and Furtado on the essence of development, once the concepts of Expansion of Potentials (Furtado) and Extension of Human Capabilities (Amartya Sen) are related to the development perspective in its human and social dimension. It was found to be possible to verify a connection between these authors, since development is understood as expansion of human capabilities and that such extension does not occur if the necessary objective conditions for its realization are not assured.

Keywords | Amartya Sen; Celso Furtado; development; human capabilities.

JEL-Code | B50; O10; O15.

\section{EL DESARROLLO COMO AMPLIACIÓN DE LAS CAPACIDADES HUMANAS: SIMILITUDES ENTRE AMARTYA SEN Y CELSO FURTADO}

\section{Resumen}

El sentido de desarrollo se ha ampliado mucho y ahora hay un reconocimiento de que el mero crecimiento económico no es necesariamente sinónimo de desarrollo. Este artículo tiene como objetivo examinar el concepto de desarrollo entendido como la ampliación de las capacidades humanas. Con este fin, se busca discutir lo que es el desarrollo basado en los conceptos desarrollados por Amartya Sen y Celso Furtado, y luego llevar a cabo un diálogo entre sus teorías. Durante el análisis se observó una proximidad entre Sen y Furtado en la esencia del desarrollo, ya que los conceptos de la Expansión de Potencialidades (Furtado) y Extensión de las Capacidades Humanas (Amartya Sen) se relacionan con la perspectiva de desarrollo en su dimensión humana y social. Se encontró que es posible verificar una conexión entre estos autores, en que el desarrollo se entiende como la expansión de las capacidades humanas y que dicha ampliación no se produce si las condiciones objetivas necesarias para su realización no están aseguradas.

Palabras-clave | Amartya Sen; capacidades humanas; Celso Furtado; desarrollo.

Código JEL | B50; O10; O15.

\section{Introdução}

O sentido do termo desenvolvimento muito se alargou e hoje existe um reconhecimento alicerçado de que crescimento econômico não é sinônimo de desenvolvimento. Para que haja desenvolvimento é preciso mais que bons resultados econômicos e outras dimensões, como a humana, a social e a ambiental, é preciso também avançar para que de fato se tenha desenvolvimento. E, não raro, pode-se observar consequências danosas do ponto de vista social, cultural e ambiental de um modelo de desenvolvimento centrado unicamente na perspectiva econômica. 
A noção de desenvolvimento tem como referência, na maioria dos casos, uma definição que vislumbra o aumento de produtividade, acumulação de capital e renda real per capita como os aspectos mais relevantes do desenvolvimento econômico, sobretudo nas sociedades capitalistas. Entre os fenômenos mais estudados pela Sociologia estão as condições políticas que tornam possível a formação do mercado e a afirmação da livre empresa, mas também fatores culturais na origem do espírito capitalista, formação do empreendedorismo etc. Para diferenciar-se da ciência econômica, as ciências sociais irão considerar como outros determinantes - ideológicos, religiosos, culturais, políticos e psicológicos etc. - interferem na maneira como variados grupos políticos e sociais distribuem os recursos provenientes do setor produtivo (GALLINO, 2005).

$\mathrm{Na}$ verdade, desde o século passado, Celso Furtado (2011) atentava para o fato de que a ideia de desenvolvimento se refere diretamente à realização das potencialidades humanas. De forma que, segundo ele, o desenvolvimento acontece quando a expansão da capacidade criativa dos homens, nas técnicas produtivas e na formulação de valores existenciais, conduz à sua autodescoberta, enriquecendo seu mundo de valores materiais e espirituais e atingindo vastos segmentos da coletividade.

Também sob essa ótica, elucida Amartya Sen, com muita ênfase, que a liberdade (as liberdades substantivas) é o fim primordial e o meio principal do desenvolvimento. Por isso afirma: "O êxito de uma sociedade deve ser avaliado, nesta visão, primordialmente segundo as liberdades substantivas que os membros dessa sociedade desfrutam." (SEN, 2010, p. 33). Para Sen a utilidade da riqueza está nas coisas que ela nos permite fazer, as liberdades substantivas que ela nos ajuda a obter. Nessa visão, a riqueza não é um fim em si mesmo, mas um caminho para se ter o tipo de vida que se valoriza.

Observa-se, portanto, uma aproximação entre as visões de Furtado e Sen acerca da essência do desenvolvimento. Os conceitos de Expansão das Potencialidades (Celso Furtado) ou Alargamento das Capacidades Humanas (Amartya Sen) estão ambos relacionados à perspectiva do desenvolvimento em sua dimensão humana e social.

Dessa forma, pensando no desenvolvimento econômico como requisito para o desenvolvimento social, quer de nações, quer de indivíduos, indaga-se: o que é desenvolvimento na perspectiva do alargamento das capacidades humanas? Objetiva-se, assim, analisar o conceito de desenvolvimento como alargamento das capacidades humanas. Para tanto, busca-se discorrer brevemente sobre o entendimento ao longo do tempo acerca do que seja desenvolvimento; analisar o conceito de desenvolvimento segundo Amartya Sen e o conceito de desenvolvimento segundo Celso Furtado.

Com relação à metodologia utilizada para o desenvolvimento deste estudo, tem-se uma pesquisa bibliográfica, que, segundo Vergara (2004, p. 48), é um "estudo 
sistematizado desenvolvido com base em material publicado em livros, revistas, jornais, redes eletrônicas, isto é, material acessível ao público em geral". Assim, este estudo se deu a partir da técnica análise de conteúdo dos principais textos dos autores utilizados.

\section{Contextualização do conceito de desenvolvimento}

O conceito de desenvolvimento é algo em construção e, como concordam alguns teóricos contemporâneos, é um conceito de definição complexa e fugidia. Apesar disso, é possível verificar uma demarcação geral no entendimento do que seja desenvolvimento: a concepção de crescimento econômico como sinônimo de desenvolvimento e a concepção de que o crescimento econômico seja requisito para o desenvolvimento.

José Eli da Veiga (2008) faz uma demarcação concisa dos entendimentos mais relevantes acerca do desenvolvimento ao longo do tempo. Para ele, existem três tipos básicos de resposta à indagação "o que é desenvolvimento?”.

A primeira resposta é tratar o desenvolvimento como sinônimo de crescimento econômico. Nessa perspectiva, mede-se o desenvolvimento exclusivamente a partir de indicadores econômicos como o Produto Interno Bruto (PIB), Produto Nacional Bruto (PNB) etc. Veiga (2008) observa que até a década de 1960 não havia a necessidade de distinguir desenvolvimento de crescimento econômico, pois as poucas nações desenvolvidas eram as que haviam se tornado ricas pela industrialização. Entretanto, foram surgindo evidências de que o intenso crescimento econômico ocorrido durante a década de 1950 em várias nações semiindustrializadas (como o Brasil) não se traduziu em maior acesso das populações pobres a bens materiais e culturais, como ocorrera nos países considerados desenvolvidos. Outrossim, é possível verificar que, com a criação do Índice de Desenvolvimento Humano (IDH), ficou constrangedor ver apenas o aspecto econômico na menção ao desenvolvimento.

A segunda resposta é a de afirmar que o desenvolvimento não passa de simples ilusão, crença, mito ou manipulação ideológica. Segundo Veiga (2008), os principais expoentes dessa corrente foram Giovanni Arrighi, Oswaldo de Rivero, Majid Rahnema e Gilbert Rist. O primeiro, sociólogo italiano, cujas ideias tiveram bastante repercussão no Brasil, apregoava não haver chances factíveis de ocorrer mobilidade ascendente na rígida hierarquia da economia capitalista mundial, de forma que os dois golfos (países periféricos e países centrais) seriam uma realidade praticamente imutável; ele sustentava sua visão com base no estudo da distribuição da população mundial pelo PNB per capita no período de 1938-1983.

Veiga (2008) considera melhor articulada a argumentação dos diplomatas Oswaldo de Rivero e Majid Rahnema e do scholar suíço Gilbert Rist. Rivero aponta que a 
questão da própria formação da nação (ser nação antes de ser Estado), da miséria científico tecnológica, da explosão demográfica, das efêmeras rendas estratégicas obtidas por países subdesenvolvidos durante a Guerra Fria são condições que fazem com que seja tão difícil transpor a realidade do subdesenvolvimento. De forma geral, Veiga (2008) conclui não haver consenso entre os que veem desenvolvimento como quimera, sendo a tese de Arrighi a mais equívoca.

Usando o trocadilho Sen-sacional em referência a Amartya Sen, Veiga (2008) formula a melhor resposta até agora para a definição do conceito: desenvolvimento é intrinsecamente relacionado à liberdade, de forma que a liberdade exerce papel constitutivo e instrumental do desenvolvimento. Nessa abordagem, a expansão da liberdade é considerada o fim primordial e o principal meio do desenvolvimento, os quais são chamados de papel constitutivo e papel instrumental, respectivamente. O papel constitutivo relaciona-se à importância da liberdade substantiva no enriquecimento da vida humana. As liberdades substantivas incluem capacidades elementares como, por exemplo, ter condições de evitar privações como a morte prematura, como também as liberdades associadas a saber ler e fazer cálculos aritméticos, ter participação política, liberdade de expressão etc.

Neste momento, portanto, propõe-se trazer a "voz" do próprio Sen (2010) para melhor compreender seu entendimento sobre a essência do desenvolvimento.

\section{O desenvolvimento na perspectiva de Amartya Sen}

Para fundamentar sua teoria acerca do desenvolvimento, Sen (2010) inicia remetendo a uma reflexão sobre o papel da riqueza na vida das pessoas, a relação entre rendas e realizações. Para ele, a lacuna entre as duas perspectivas sobre o significado do desenvolvimento (a perspectiva da concentração exclusiva na riqueza econômica e a de um enfoque mais amplo sobre a vida que podemos levar) é uma questão fundamental na conceituação do desenvolvimento.

Citando Aristóteles, conclui que a riqueza é um meio em proveito de alguma outra coisa. Para ele, a "alguma coisa" a que se quer chegar é, em última instância, a liberdade para se levar o tipo de vida que se almeja, pois "a utilidade da riqueza está nas coisas que ela nos permite fazer - as liberdades substantivas que ela nos ajuda a obter." (SEN, 2010, p. 28).

O autor elenca basicamente duas formas de liberdades: a liberdade de sobreviver, e a liberdade política e de exercício dos direitos civis. Em relação à primeira, considerando um contexto de privação, ele menciona fome, subnutrição e/ou falta (ou precariedade) de acesso a serviços básicos de saúde, saneamento e água tratada; e sobre a segunda, os regimes de governo e/ou sistemas que usurpam as liberdades política e de exercício dos direitos civis. $\mathrm{O}$ autor ainda reforça o valor 
do segundo tipo de liberdade, independente mesmo dos efeitos sobre a economia. Dessa forma, "como as liberdades políticas e civis são elementos constitutivos da liberdade humana, sua negação é, em si, uma deficiência." (SEN, 2010, p. 31).

$\mathrm{O}$ autor lista esses dois papeis elementares da liberdade e justifica-os. Quanto ao papel de expansão das capacidades, ele argumenta que essas capacidades podem ser aumentadas pelas políticas públicas; e a direção dessas políticas pode ser influenciada pelo uso efetivo das capacidades participativas do povo.

É possível aqui fazer um contraponto com a discussão sobre capital social no que diz respeito às condições de fomento deste; há um debate entre os autores da temática e uma subdivisão entre os que consideram a cultura como fator determinante para a existência ou inexistência de capital social, ideia atribuída principalmente a Robert Putman (1996), e os que defendem que localidades culturalmente apáticas não estão condenadas a sê-lo para sempre, ou que não seja tão difícil essa mudança, uma vez que se criem as condições necessárias para realizá-las (ABU-EL-HAJ, 1999).

Quanto ao papel de principal determinante da iniciativa individual e eficácia social, Amartya Sen (2010, p. 33) afirma que "ter mais liberdade melhora o potencial das pessoas para cuidar de si mesmas e para influenciar o mundo, questões centrais para o processo de desenvolvimento". Nesse sentido, ele aborda a condição de agente, ou seja, o indivíduo como membro do público e participante de ações econômicas, sociais e políticas. Sen fundamenta esse ponto com base na importância da participação cidadã com vistas à garantia dos interesses públicos na tomada de decisões governamentais. E interessa a este trabalho exatamente o processo de alargamento das capacidades humanas para usufruto não somente particular, mas, sobretudo, para o uso social e comunitário, uma vez que o desenvolvimento é compreendido e desejado como a emancipação do ser humano de si mesmo e das pressões sociais para si mesmo e para a construção de uma realidade melhor.

Outro aspecto importante que Sen (2010) evidencia são os contrastes verificados em economias de crescimento econômico elevado, nas quais há os com grande êxito no aumento da duração e qualidade de vida e os sem esse êxito. Economias com grande êxito no aumento e duração da qualidade de vida, nas quais figuram as com grande crescimento econômico, e as com inexpressivo crescimento econômico.

Sen (2010) vale-se ainda de outro fato curioso para mostrar o quanto outros fatores que não os de renda podem favorecer a melhoria das condições de vida humana. Ele cita a redução da mortalidade na Grã-Bretanha no século XX, especialmente durante as duas Grandes Guerras Mundiais, concluindo que os programas sociais não funcionaram por si só, mas que uma mudança no grau de compartilhamento social durante as guerras favoreceram a redução da mortalidade 
na época. Em síntese, trata-se de uma questão de comportamento humano: a união e a solidariedade impactaram sobre as condições de vida dos ingleses.

Verifica-se nas discussões acerca da teoria de Sen uma acusação de que ele seja um liberal desalmado, um soldado da ideologia que protege os opressores. No entanto, quando ele fala em liberdade e responsabilidade individual ele não deixa de enfatizar que, embora não exista substituto para a responsabilidade individual, "as liberdades substantivas que desfrutamos para exercer nossas responsabilidades são extremamente dependentes das circunstâncias pessoais, sociais e ambientais" (SEN, 2010, p. 631). De forma que o apoio social para expandir as liberdades das pessoas deve ser visto como um argumento favorável à responsabilidade individual e não contra ela, pois sem a garantia das liberdades substantivas e das capacidades para realizar algo, uma pessoa não pode ser responsável por sua realização ou irrealização. Assim destaca:

Há uma diferença entre 'pajear' as escolhas de um indivíduo e criar mais oportunidades de escolha e decisões substantivas para as pessoas, que então poderão agir de modo responsável sustando-se nessa base. $\mathrm{O}$ comprometimento social com a liberdade individual obviamente não precisa atuar apenas por meio do Estado; deve envolver também outras instituições: organizações políticas e sociais, disposições de bases comunitárias, instituições não governamentais de vários tipos, a mídia e outros meios de comunicação e entendimento público, bem como as instituições que permitem funcionamento de mercados e relações contratuais (SEN, 2010, p. 632).

O teórico vai dizer também que é mal orientada uma pergunta recorrente na literatura sobre desenvolvimento: a democracia e os direitos políticos e civis básicos ajudam a promover o processo de desenvolvimento? Para ele, podemos ver a emergência e a consolidação desses direitos como constitutivas do processo de desenvolvimento, de forma que o exercício desses direitos pode cobrar mais responsividade do Estado frente às demandas sociais. Porém, o aumento das liberdades gerais e civis é crucial para o próprio processo de desenvolvimento.

Entre as liberdades relevantes inclui-se a liberdade de agir como cidadão que tem sua importância reconhecida e cujas opiniões são levadas em conta, em vez de viver como vassalo bem alimentado, bem vestido e bem entretido. [...] As capacidades que uma pessoa realmente possui dependem da natureza das disposições sociais, as quais podem ser cruciais para as liberdades individuais. E dessa responsabilidade o Estado e a sociedade não podem escapar (SEN, 2010, p. 366). 
A partir das ideias do autor, depreende-se que o mesmo não prevarica ou se omite na cobrança da responsabilidade do Estado e dos demais poderes instituídos em promover as condições que subsidiem o desempenho de uma vida digna por parte dos indivíduos de uma sociedade.

Outra questão importante que Sen (2010) realiza é diferenciar os conceitos de capital humano e capacidade humana. O primeiro diz respeito ao nível de educação, aprendizado e especialização das pessoas para as possibilidades de produção; contribuindo para o processo de expansão econômica. No entanto, a capacidade humana concentra-se no potencial das pessoas para levar a vida que elas valorizam e melhorar suas escolhas reais. Assim, segundo o autor, o conceito de capital humano é importante, mas precisa de uma suplementação, pois os seres humanos não são meramente meios de produção.

Com isso, pode-se depreender que Amartya Sen concebe o desenvolvimento a partir do indivíduo ao seu contexto social, político, econômico, histórico etc.

\section{Celso Furtado: o desenvolvimento como expansão das potencialidades humanas}

Considerando-se a vasta obra de Celso Furtado, buscou-se neste artigo debruçarse sobre as menções diretas do autor acerca da natureza do desenvolvimento. Em sua obra "Pequena Introdução ao Desenvolvimento" (1980), Furtado chama a atenção para a limitação da explicação do desenvolvimento a partir dos modelos de crescimento que ignoram os aspectos não econômicos. E, como teórico, ele tanto esboçou relações entre variáveis econômicas quanto relacionou a economia a questões políticas mais amplas.

De acordo com ele, a ideia de desenvolvimento está no centro da visão do mundo prevalecente em nossa época, e o homem é visto como um fator de transformação do mundo e de afirmação de si mesmo. De forma que, no empenho de efetivar suas potencialidades, o homem transforma o mundo e engendra $O$ desenvolvimento. Vê-se, assim, o papel que Furtado atribui ao ser humano, em sua condição de ser, no processo do desenvolvimento. O autor elucida que:

As sociedades são desenvolvidas na medida em que nelas mais cabalmente o homem logra satisfazer suas necessidades e renovar suas aspirações. O estudo do desenvolvimento tem, portanto, como tema central a invenção cultural, em particular a morfogênese social (FURTADO, 1980, p. 9).

Mediante uma compreensão de cunho estruturalista, Furtado aponta que a questão do desenvolvimento e subdesenvolvimento, especialmente no caso brasileiro, por 
ser resultado de questões econômicas e não econômicas, igualmente requer medidas estruturais nas duas frentes com vistas a alcançar, a longo prazo, mudança nos parâmetros estruturais da economia, e com isso o desenvolvimento.

Segundo o teórico, a invenção cultural ordena-se em dois eixos: (1) a ação do homem e (2) os fins a que o homem liga a própria vida. A invenção diretamente ligada à ação nos dá a técnica; e a invenção ligada aos fins, nos dá os valores (morais, religiosos, estéticos etc.). Dado que o progresso técnico possui um poder de difusão muito maior do que a criação de valores, "na civilização industrial a capacidade inventiva do homem foi progressivamente canalizada para a criação tecnológica, o que explica a formidável força expansiva que a caracteriza." (FURTADO, 1980, p. 10).

Em virtude dessa realidade, constata-se a tendência da teoria do desenvolvimento confundir-se com a explicação do comportamento do sistema produtivo capitalista.

Apesar disso, Furtado (2011) coloca que, a rigor, somente quando a capacidade criativa do homem se volta para o descobrimento de si mesmo é que se pode falar em desenvolvimento. Ele diz ainda que:

O crescimento econômico, tal qual o conhecemos, vem se fundando na preservação dos privilégios das elites que satisfazem seu afã de modernização; já o desenvolvimento se caracteriza pelo seu projeto social subjacente. [...] Dispor de recursos para investir está longe de ser condição suficiente para preparar um melhor futuro para a massa da população. Mas quando o projeto social prioriza a efetiva melhoria das condições de vida dessa população, o crescimento se metamorfoseia em desenvolvimento (FURTADO, 2004, p. 3-4).

A partir desses extratos, observa-se o quanto Celso Furtado notou as nuances profundas do desenvolvimento e como ele já percebia que o desenvolvimento compreende um processo no qual precisa haver transformação da sociedade ao nível dos meios, mas também dos fins.

\section{Aproximações teóricas entre Sen e Furtado}

A partir das ideias ora expostas dos dois autores tratados neste trabalho, vê-se que seus pensamentos dialogam. Vejam-se, por exemplo, os seguintes fragmentos: "O êxito de uma sociedade deve ser avaliado [...], primordialmente segundo as liberdades substantivas que os membros dessa sociedade desfrutam." (SEN 2010, p. 33). Observa-se que este pensamento está em concordância com o de Furtado, quando ele afirma: 
As sociedades são desenvolvidas na medida em que nelas mais cabalmente o homem logra satisfazer suas necessidades e renovar suas aspirações. O estudo do desenvolvimento tem, portanto, como tema central, a invenção cultural, em particular a morfogênese social (FURTADO, 1980, p. 9).

Além dos fragmentos de cada um dos teóricos, supracitados, é possível perceber que ambos valorizam a realidade histórica e os dados empíricos para a compreensão dos fenômenos econômicos; compreendem que esses se inserem dentro de uma realidade social que os condiciona e influencia; e compreendem que o crescimento econômico não é um fim em si mesmo, mas que o desenvolvimento implica em uma transformação do conjunto de estruturas sociais em função de objetivos a que se propõe alcançar uma determinada sociedade.

E assim, o que Sen (2010) chama de "alargamento das capacidades humanas" está em sintonia com o que Furtado (1980, 2004, 2008, 2011) chama de "expansão das potencialidades humanas", de forma que ambos entendem que desenvolvimento não é apenas garantir ao ser humano um nível adequado de renda que o possibilite ter e realizar determinadas coisas, mas que este ser humano possa também desenvolver o máximo de suas potencialidades.

\section{Considerações finais}

Observa-se que a compreensão do que seja desenvolvimento é temática sobre a qual muitos já se debruçaram, temática essa que não é fácil de definir e que necessita de várias visões e/ou abordagens para que se chegue a um entendimento mais acurado. Este estudo, ao considerar como pressuposto que crescimento econômico não é igual a desenvolvimento, já assinala que não se restringirá à abordagem economicista, antes buscará compreender melhor a interpretação que concebe o desenvolvimento como alargamento das capacidades humanas.

Com a primeira parte da discussão - evolução do conceito de desenvolvimento percebeu-se a importância de compreender o percurso do pensamento de cada uma das principais formas de concebê-lo, atentando para o contexto sóciohistórico e especialmente para os pressupostos de cada visão. Esta reflexão inicial foi importante, pois não se pode tomar uma forma de entendimento de dado fenômeno sem que se estudem as variadas formas de entendimento do mesmo.

O eixo do trabalho se situou em apresentar e analisar a concepção de desenvolvimento em Amartya Sen e Celso Furtado. Constatou-se que é possível verificar uma aproximação entre esses dois autores, na medida em que o cerne do desenvolvimento é entendido como o alargamento das capacidades humanas e que tal 
alargamento não ocorre se não forem asseguradas as devidas condições objetivas para a sua realização.

\section{Referências}

ABU-EL-HAJ, Jawdat. O debate em torno do capital social: uma revisão crítica. Revista Brasileira de Informação Bibliográfica em Ciências Sociais (BIB), Rio de Janeiro, n. 47, p. 65-79, $1^{\circ}$ semestre de 1999.

FURTADO, Celso. El desarrollo como proceso endógeno. Enero - abril, 2011. Disponível em: <http://www.olafinanciera.unam.mx/new_web/08/pdfs/ Furtado-Clasicos-OlaFin-8.pdf>. Acesso em: 26 jun. 2014.

Os desafios da nova geração. Jornal dos economistas, Rio de Janeiro, n. 179, jun., p. 3-4, 2004.

- Pequena introdução ao desenvolvimento: enfoque interdisciplinar. São Paulo: Ed. Nacional, 1980.

. Economia do desenvolvimento. Curso Ministrado na PUC/SP em 1975. Centro Internacional Celso Furtado. Rio de Janeiro: Contraponto, 2008.

GALLINO, Luciano. Dicionário de sociologia. São Paulo: Paulus, 2005.

PUTNAM, R. D. Comunidade e democracia: a experiência da Itália Moderna. Rio de Janeiro: FGV, 1996.

SEN, Armatya. Desenvolvimento como liberdade. São Paulo: Companhia das Letras, 2010.

VEIGA, José Eli da. Desenvolvimento sustentável: o desafio do século XXI. 3 ed. Rio de Janeiro: Garamond, 2008. 
Endereço para correspondência:

Dellany Maria Dantas Souza - delydantas@yahoo.com.br

Rua Baraúnas, 351, Centro de Integração Acadêmica, $3^{\circ}$ andar, Sala 311 58429-500 Campina Grande/PB, Brasil

Angela Maria Cavalcanti Ramalho - angelaramalho@oi.com.br Rua Baraúnas, 351, Centro de Integração Acadêmica, $3^{\circ}$ andar, Sala 311 58429-500 Campina Grande/PB, Brasil

Leonardo de Araíjo e Mota - la-mota@uol.com.br Rua Baraúnas, 351, Centro de Integração Acadêmica, $3^{\circ}$ andar, Sala 311 58429-500 Campina Grande/PB, Brasil 